\title{
Article
}

\section{ZnOTe Compounds Grown by DC-Magnetron Co-Sputtering}

\author{
Olga Sánchez ${ }^{1, *(\mathbb{D})}$ and Manuel Hernández-Vélez ${ }^{2}$ \\ 1 Instituto de Ciencia de Materiales de Madrid (CSIC), 28049 Madrid, Spain \\ 2 Applied Physics Department, Universidad Autónoma de Madrid (UAM), 28049 Madrid, Spain; \\ manuel.hernandez@inv.uam.es \\ * Correspondence: olgas@icmm.csic.es
}

Citation: Sánchez, O.;

Hernández-Vélez, M. ZnOTe

Compounds Grown by

DC-Magnetron Co-Sputtering.

Coatings 2021, 11, 570.

https://doi.org/10.3390/

coatings 11050570

Academic Editors: Rainer Hippler and Roman A. Surmenev

Received: 27 February 2021

Accepted: 11 May 2021

Published: 14 May 2021

Publisher's Note: MDPI stays neutral with regard to jurisdictional claims in published maps and institutional affiliations.

\begin{abstract}
ZnOTe compounds were grown by DC magnetron cosputtering from pure Tellurium (Te) and $\mathrm{Zinc}(\mathrm{Zn})$ cathodes in $\mathrm{O}_{2} / \mathrm{Ar}$ atmosphere. The applied power on the $\mathrm{Zn}$ target was constant equal to $100 \mathrm{~W}$, while the one applied on the Te target took two values, i.e., $5 \mathrm{~W}$ and $10 \mathrm{~W}$. Thus, two sample series were obtained in which the variable parameter was the distance from the Te targets to the substrate. Sample compositions were determined by Rutherford Backscattering Spectroscopy (RBS) experiments. Structural analysis was done using X-Ray diffraction (XRD) spectrometry and the growth of the hexagonal $\mathrm{w}-\mathrm{ZnO}$ phase was identified in the XRD spectra. RBS results showed high bulk homogeneity of the samples forming ZnOTe alloys, with variable Te molar fraction (MF) ranging from $0.48-0.6 \%$ and from $1.9-3.1 \%$ for the sample series obtained at $5 \mathrm{~W}$ and $10 \mathrm{~W}$, respectively. The results reflect great differences between the two sample series, particularly from the structural and optical point of view. These experiments point to the possibility of Te doping $\mathrm{ZnO}$ with the permanence of intrinsic defects, as well as the possibility of the formation of other Te solid phases when its content increases. The results and appreciable variations in the band gap transitions were detected from Photoluminescence (PL) measurements.
\end{abstract}

Keywords: DC magnetron cosputtering; ZnOTe alloy; XRD patterns; RBS experiments; PL characterization

\section{Introduction}

Zinc Oxide $(\mathrm{ZnO})$ is a well-known II-VI semiconductor with direct band gap around $3.37 \mathrm{eV}$ and large exciton binding energy $(60 \mathrm{meV})$ at room temperature [1]. Nowadays, $\mathrm{ZnO}$ and $\mathrm{ZnO}$-based materials are recognized in a wide spectrum of applications, which make them into unique materials because of the combination of multiple functional properties including electronics and human healthcare. However, the large range of industrial uses is strongly dependent on the experimental technique, parameters, preparation, and post-treatment of the grown samples etc. Optimizing these factors is the greatest challenge in obtaining these materials' benefits.

Multiple research projects and the discovery of new applications for materials based on $\mathrm{ZnO}$ made this semiconductor the focus of important high-technology advances, such as optoelectronic devices, particularly those based on $\mathrm{ZnO}$ nanostructured for light emitters [2,3]. $\mathrm{ZnO}$ thin film transistors under ultraviolet irradiation [4], broad band photo-absorption architectures from UV-IR [5], gas sensors [6], acoustic wave devices, solar cells, transparent electronic and flat panel displays [7-9], and photo-catalytic applications [10] etc. The $\mathrm{ZnO}$ wideband gap and transparency in thin film form makes it a prominent candidate for use in multiband materials, especially for enhancing solar cell efficiency [11]. Great challenges in the last decade include synthesizing $\mathrm{ZnO}$-based materials that allow for control over p-type doping $[12,13]$ and building $\mathrm{n}$ - and $\mathrm{p}$ - type based semiconductor junctions [14]. Currently, ternary compounds combining $\mathrm{Zn}, \mathrm{O}$, and Te atoms acquired great significance for developing Highly Mismatched Alloys (HMA) mainly with the goal of enhancing solar cell efficiency. The band structure obtained this way is well-described by the band anticrossing 
(BAC) model [15], which showed that dilute impurities lead to an unusual energy band structure with a narrow band of states located in the band gap of the host material [16,17]. In particular, Te may provide advantages if it is used as an isoelectronic dopant [18,19]. $\mathrm{Up}$ to now, both undoped $\mathrm{ZnO}$ and $\mathrm{ZnO}$ :Te alloys as well as $\mathrm{ZnTe:O}$ were grown using several deposition techniques, such as: ion implantation followed by pulsed laser melting (PLM) [20], chemical precipitation [10], molecular beam epitaxy (MBE) [12], atomic layer deposition [21], hydrothermal method [22,23] etc. Recently, Ting et. al. [24] published an interesting paper dealing with different parameters affecting the growth of $\mathrm{ZnTeO}$ alloys and their influence in band gap modulation. In the field of Sputtering deposition techniques, RF magnetron sputtering is the most common $[25,26]$, particularly with ZnTe as the unique target, to obtain $\mathrm{ZnTeO}$ alloys [27]. Recently, RF magnetron sputtering using two independent targets of $\mathrm{ZnTe}$ and $\mathrm{ZnO}$ was also used [28]. All these techniques were used indistinctly for both ZnO-based thin films and nanostructured compounds. Nevertheless, there are few reports on DC magnetron sputtering for growing such materials and even less for those using the DC cosputtering magnetron. The main objective of this basic research was to study the effects of low and middle Te concentrations in the $\mathrm{ZnO}$ network which currently constitute an interesting scientific issue. For this purpose, $\mathrm{ZnO}$ :Te thin films with different Tellurium atomic content and without any intentional heating were grown by using two separate, highly pure, and independent targets of Te and Zn. Under these experimental conditions, we were able to get high control of the $\mathrm{ZnOTe}$ thin film composition. Sputtering deposition is widely used for thin films growth because of its ability to cover large surface areas, which makes it easy to scale to an industrial level at a relatively low cost. We carried out compositional, structural, and optoelectronic characterization to study the influence of Te content on the macroscopic properties of the samples. As far as we know, this is the first report of the growth and procedures to obtain ZnOTe alloys by DC magnetron cosputtering technique with independent $\mathrm{Zn}$ and Te cathodes.

\section{Materials and Methods}

ZnO:Te films were deposited onto monocrystalline $(<100>)$ n-type silicon substrates by using a DC magnetron cosputtering system. The reaction chamber consists of a vacuum cylindrical enclosure where two circular, $7.62 \mathrm{~cm}$ in diameter planar magnetrons are located. The distance between them was set at $60^{\circ}$ so that the samples were exposed to both cathodes during the growth processes. Then the substrates were cleaned in successive ultrasonic baths (acetylene trichloro, acetone, ethanol, and deionized water) to degrease and to eliminate rests of strange materials on their surfaces. Finally, they were dried under nitrogen flow. Highly pure commercial Zinc $(99.99 \%)$ and Tellurium $(99.99 \%)$ were used as targets (cathodes). All experiments were performed in an $\mathrm{Ar}(99.999 \%)$ and $\mathrm{O}_{2}(99.992 \%)$ atmosphere keeping the $\mathrm{O}_{2} / \mathrm{Ar}$ ratio equal to $0.24 \%$, and deposition time was maintained at $30 \mathrm{~min}$. The chamber was pumped out to a base pressure of $3 \times 10^{-4} \mathrm{~Pa}$ with the working pressure equal to $7 \times 10^{-1} \mathrm{~Pa}$. The $\mathrm{Zn}$-cathode distance to the substrate $\left(\mathrm{D}_{\mathrm{Zn}-\mathrm{S}}\right)$ and the applied power on the $\mathrm{Zn}$ target $\left(\mathrm{P}_{\mathrm{Zn}}\right)$ remained constants, equal to $15 \mathrm{~cm}$ and 100 $\mathrm{W}$ respectively. These experimental parameters are the optimal parameters for obtaining highly stoichiometric and crystalline $\mathrm{ZnO}$ thin films, as we previously reported [29].

Prior to deposition, the targets were presputtered for $10 \mathrm{~min}$ to remove any impurity on their surfaces. The samples were grown after the total poisoning of the cathodes working under the reactive sputtering regime. We reported that higher Te content leads to faster $\mathrm{ZnO}$ structure amorphization [29]. To deepen the study on the effects of the incorporation of $\mathrm{Te}$ in $\mathrm{ZnO}$ structure and the experimental conditions, two sample series ( $\mathrm{A}$ and $\mathrm{B}$ ) were obtained in the present study; the experimental conditions are displayed in Table 1 . The film thicknesses were measured using a mechanical stylus profilometer (Veeco Dektak 150, Plainview NY, USA). 
Table 1. Sample labels, experimental parameters, and thicknesses. $\mathrm{D}_{\mathrm{Te}-\mathrm{S}}$ : Te: cathode-sample relative distance; $\mathrm{P}_{\mathrm{Te}}$ : power applied on Te and $\mathrm{Zn}$ target, $\mathrm{D}_{\mathrm{Zn}-\mathrm{S}}$ : $\mathrm{Zn}$ cathode-substrate relative distance; $\mathrm{h}_{\mathrm{p}}$ : sample thicknesses.

\begin{tabular}{cccccc}
\hline Sample Series & Sample Label & $\mathbf{P}_{\mathrm{Te}}(\mathbf{W})$ & $\mathbf{D}_{\mathrm{Te}-\mathrm{S}}(\mathbf{c m})$ & $\mathbf{D}_{\mathbf{Z n}-\mathbf{S}}(\mathbf{c m})$ & $\mathbf{h}_{\mathbf{p}}(\mathbf{n m})$ \\
\hline $\mathrm{ZnO}$ & $\mathrm{TO}$ & 0 & - & & 210 \\
\hline \multirow{2}{*}{$\mathrm{A}$} & $\mathrm{T} 51$ & 5 & 22 & & 235 \\
& $\mathrm{~T} 52$ & & 18.5 & 15 & 220 \\
& $\mathrm{~T} 53$ & & 22 & & 200 \\
\hline \multirow{2}{*}{$\mathrm{B}$} & $\mathrm{T} 101$ & 10 & 18.5 & 15 & 200 \\
& $\mathrm{~T} 102$ & & 15 & & 210 \\
\hline
\end{tabular}

Sample compositions were determined by Rutherford Backscattering Spectroscopy (RBS) in the 5 MV HVEE Tandetron accelerator at the Micro-Analysis Centre of Materials (CMAM) at the Universidad Autónoma de Madrid (UAM). To register RBS spectra, a He beam $(3070 \mathrm{keV})$ with scattering angle of $170.5^{\circ}$ was used. At this energy, the scattering cross section with oxygen shows a resonance increasing the Rutherford value by a factor of almost 25 [30]. RBS spectra were simulated using SIMNRA software [31]. The samples' thicknesses were also measured with this technique to compare them with that of those measured by profilometry. X-Ray Diffraction (XRD) spectra were registered with a Siemens D-5000 Diffractometer (Berlin, Germany) using grazing incidence geometry ( $\mathrm{Cu}$ anode; $\mathrm{K} \alpha=0.1542 \mathrm{~nm}$ ) with a fixed incidence angle of $0.5^{\circ}$ at room temperature to determine the crystalline structure of the films. Transmission spectrophotometry spectra were registered by using a SolidSpec-3700 Spectrophotometer (Shimadzu, Kyoto, Japan) in the range of 190$800 \mathrm{~nm}$. Photoluminescence (PL) measurements in the UV-Visible range were also carried out by means of a Labram system model HR800 UV (Horiba, Kyoto, Japan) provided with a He-Cd laser (325 nm).

\section{Results and Discussion}

\subsection{Film Composition and RBS Analysis}

Fitting of the RBS spectra was done by means of thin layers composed of nonstoichiometric compounds of $\mathrm{Zn}, \mathrm{Te}$, and $\mathrm{O}$ atoms along their thicknesses. Simulated RBS spectra (as illustrated in Figure 1) were adjusted, editing each sample composition with a small number of layers indicative of high homogeneity in the distribution of the elements in depth. The resulting empirical formulas shown in Table 2 reflect the high chemical composition control reached by DC magnetron cosputtering technique and the experimental procedures used in this work. From the empirical formulas, it is notable that in the case of the A sample series, the Te atomic percent ranges from $0.48-0.6 \%$, while in the B sample series, this parameter ranges from $1.9-3.1 \%$ over the entire atomic composition of the samples. It is expected that this marked difference of an order of magnitude in Tellurium content between both series leads to significant changes in their macroscopic properties. It can be considered a strong agreement between the thickness values obtained by profilometry and RBS measurements (see $h_{P} / h_{1}$ ratio in Table 2 ). Regarding the excess oxygen detected in all samples, it is linked to the growing atmosphere. This excess with respect to the Zinc element is shown in the right column in Table 2. Also of note are the different Te incorporations in both series depending on the relative distances between $\mathrm{Te}$ cathode and the substrate $\mathrm{D}_{\text {Te-S, }}$, particularly drawing attention to the case of sample series B. The different behavior of the ratios $\mathrm{Te} / \mathrm{Zn}$ and $\mathrm{Te} / \mathrm{O}$ are represented in Figure 2. 




Figure 1. Rutherford Backscattering Spectroscopy (RBS)-fitted spectra from all samples. Zoom inset shows the different $\mathrm{Zn}$ and Te concentration profiles more clearly.

Table 2. RBS thicknesses; $h_{p} / h_{1}$ : Profilometry/RBS thicknesses ratio; [Te]: Te Molar Fraction $\times 10^{15}$ Atoms $/ \mathrm{cm}^{2}$; ECF: Empirical Chemical Formula and O/Zn: Oxygen/Zinc atomic composition ratio.

\begin{tabular}{|c|c|c|c|c|c|}
\hline Sample & $\mathrm{h}_{1}[\mathrm{~nm}]$ & $h_{p} / h_{1}$ & [Te]: MF & ECF & $\mathrm{O} / \mathrm{Zn}$ \\
\hline T0 & & & 0 & $\mathrm{Zn}_{0 \cdot 44} \mathrm{O}_{0.56}$ & 1.27 \\
\hline T51 & 246.5 & 0.95 & 0.0048 & $\mathrm{Zn}_{0 \cdot 481} \mathrm{O}_{0 \cdot 514} \mathrm{Te}_{0 \cdot 0048}$ & 1.07 \\
\hline T52 & 212.5 & 1.03 & 0.0056 & $\mathrm{Zn}_{0 \cdot 468} \mathrm{O}_{0.526} \mathrm{Te}_{0.0056}$ & 1.12 \\
\hline $\mathrm{T} 53$ & 213.8 & 0.94 & 0.006 & $\mathrm{Zn}_{0 \cdot 474} \mathrm{O}_{0.52} \mathrm{Te}_{0.006}$ & 1.1 \\
\hline $\mathrm{T} 101$ & 187 & 1.09 & 0.019 & $\mathrm{Zn}_{0.465} \mathrm{O}_{0.516} \mathrm{Te}_{0.019}$ & 1.11 \\
\hline T102 & 218.42 & 0.95 & 0.026 & $\mathrm{Zn}_{0 \cdot 444} \mathrm{O}_{0 \cdot 53} \mathrm{Te}_{0 \cdot 026}$ & 1.19 \\
\hline T103 & 214.98 & 0.98 & 0.031 & $\mathrm{Zn}_{0 \cdot 45} \mathrm{O}_{0.519} \mathrm{Te}_{0.031}$ & 1.15 \\
\hline
\end{tabular}

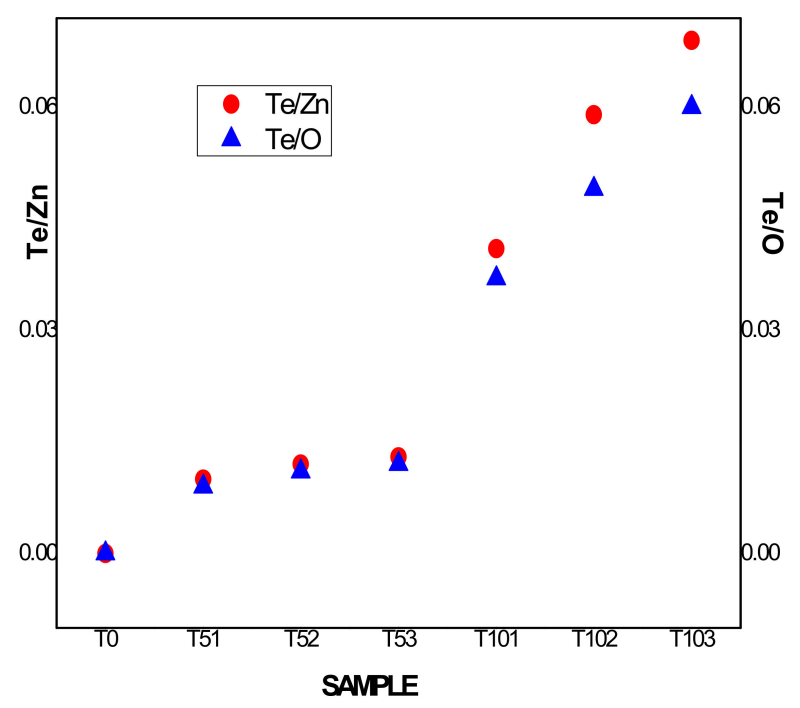

Figure 2. $\mathrm{Te} / \mathrm{Zn}$ and $\mathrm{Te} / \mathrm{O}$ ratios behavior for both sample series. 
While in series $\mathrm{A}$, both ratios increased very slowly, tending to a saturation value around 0.013 , in series B, both atomic ratios increased almost monotonically and inversely proportional to the distance between the Te cathode and the substrate. Evidently, in our experimental conditions for the lowest $\mathrm{P}_{\mathrm{Te}}$ applied on the Tellurium cathode, the parameter $\mathrm{D}_{\mathrm{Te}-\mathrm{S}}$ did not have a significant role in the Te incorporation into the films, in contrast with sample series $\mathrm{B}$ which obtained with the highest $\mathrm{P}_{\mathrm{Te}}$ value. In this case, the following microscopic events could have happened:

(a) Partial substitution of $\mathrm{Zn}$ by Te atoms in the $\mathrm{ZnO}$ crystalline structure is possible since it is higher in sample series B.

(b) Considering the increasing Te content and oxygen excess, it is possible the $\mathrm{Zn}$ vacancies or interstitials were quenched by oxygen ionic species or oxygen substitution by Te atoms in different chemical ionization states.

(c) Formation of other nonstoichiometric and probably amorphous Te-O compounds. Neither were discarded.

All the above phenomena could take place in one sample at the same time depending on multiple experimental parameters, on the chemical ionization states, and the concentrations of impurities. Additional in-depth studies to elucidate those extremes are needed.

\subsection{Crystalline Structure}

XRD spectra of the A and B sample series are shown in Figure 3a,b, respectively. In both figures, the spectra were displaced vertically for clarity. The reference spectrum from $\mathrm{ZnO}$ appears at the top of Figure 3 to facilitate comparison. The intensities and Full Width at Half Maximum (FWHM) from the main crystallographic orientations point to a low crystalline quality in this reference. Vertical black dot lines were drawn as a visible guide for identifying positions of the main Bragg reflections detected after Gaussian adjustment of the peaks identified in the $\mathrm{ZnO}$ diffractogram. The main crystallographic orientations denoting the formation of polycrystalline hexagonal phase [32] $\mathrm{w}-\mathrm{ZnO}$ is more strongly manifested in the spectra of samples with the lowest Te content in both series. In sample series A (as illustrated in Figure 3a), for sample T51, the Bragg reflections observed in the $\mathrm{w}-\mathrm{ZnO}$ reference are clearly identified. However, the peak associated with the $<101>$ crystallographic orientation of $\mathrm{w}-\mathrm{ZnO}$ becomes the most intense, instead of the one corresponding to $<002>$ crystallographic orientation as is generally accepted for this $\mathrm{ZnO}$ phase. On the other hand, it is possible to identify a very weak Bragg reflection in this sample, around $2 \theta=43.21^{\circ}$, which was attributed to the $<220>$ crystallographic orientation of $\mathrm{ZnTe}$ cubic phase (b-ZnTe) [33,34]. In this series, for higher Te content, i.e., samples T52 and T53, the <002> crystallographic orientation becomes prominent. It is significant that in the T53 sample diffractogram with the highest Te content, the $\mathrm{w}-\mathrm{ZnO}$ structure was noticeably weakened, with the presence of a unique broad peak along the $<002>$ orientation. These observations can lead to the suspicion that important structural changes occurred in the samples with increasing Te content which will be more evident in the following analysis. Particularly, in the aforementioned fits, slight shifts were observed in the positions of the most pronounced diffraction peaks characterizing $\mathrm{w}-\mathrm{ZnO}$ with the incorporation of Te atoms in its framework.

This fact is displayed in Table 3. We found that the FWHM of the diffraction peaks increases considerably for all samples relative to their counterparts in the reference sample. Especially in sample T103, this parameter could achieve more than nine units of difference with respect to that estimated for the same Bragg reflection in the sample reference. The latest agree with the loss of $\mathrm{w}-\mathrm{ZnO}$ crystalline quality when Te content increases as mentioned above. 

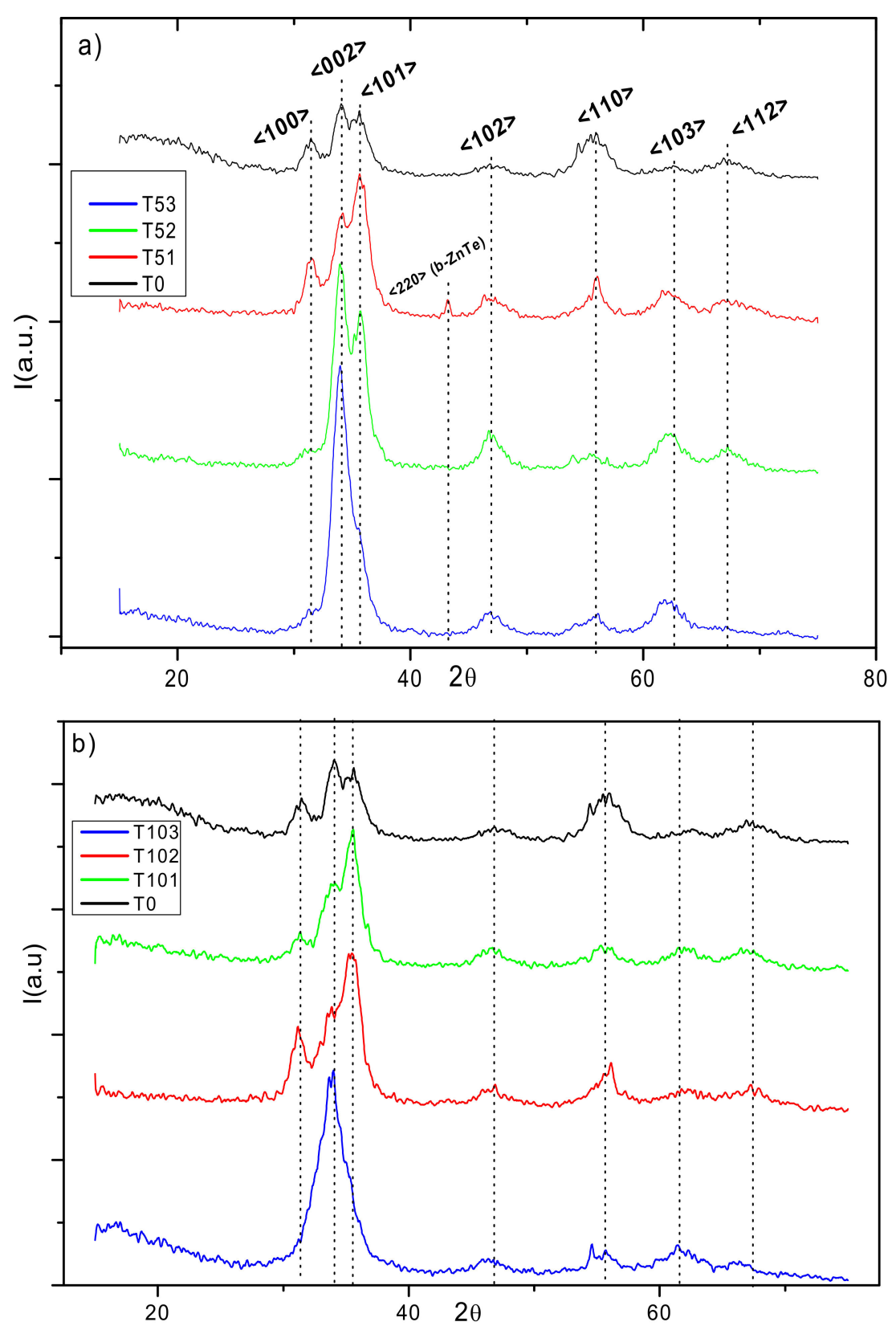

Figure 3. X-Ray Diffraction (XRD) spectra of (a) sample series A and (b) sample series B. The $\mathrm{XRD}$ spectrum of $\mathrm{ZnO}$ appears at the top as reference. Vertical black dot lines aim to facilitate the identification of the main crystallographic orientations of reference. The spectra were displaced vertically for clarity.

Table 3. $2 \theta$ position variations of main crystallographic orientation from $\mathrm{w}-\mathrm{ZnO}$ as $\mathrm{Te}$ content increases for all samples. NI stands for Not Identifiable.

\begin{tabular}{lccccccc}
\hline $\begin{array}{l}\text { Cristallog. } \\
\text { Orientation.ZnO ref. }\end{array}$ & T51 & T52 & T53 & T101 & T102 & T103 \\
\hline$<100>$ & 31.8 & 31.5 & 30.9 & NI & 31.2 & 31.2 & NI \\
$<002>$ & 34.5 & 34.02 & 33.98 & 34.2 & 33.8 & 33.8 & 33.9 \\
$<101>$ & 36.2 & 35.7 & 35.7 & NI & 35.5 & 35.5 & NI \\
\hline
\end{tabular}

The shift to smaller angles indicates an increase in the interplanar distances, which implies the possibility of Tellurium incorporation into the $\mathrm{ZnO}$ network, substituting either 
$\mathrm{Zn}$ or $\mathrm{O}$ atoms [10]. The diffractograms of sample series B are shown in Figure $3 \mathrm{~b}$. A weak although recognizable $\mathrm{w}-\mathrm{ZnO}$ phase is present in all spectra. In this case, the $<101>$ crystallographic orientation is predominant in samples T101 and T102, as it was in sample T51 from series A. However, here, sample T103 with the highest Te content in absolute terms shows only a very wide band centered at $2 \theta=33.9$, which could be also associated with the $\mathrm{w}-\mathrm{ZnO}<002>$ crystallographic orientation as the best approximation. This band is broader than that observed in sample T53 at $2 \theta=34.2$ degrees. In this sample series, it is also possible to detect a slight drift to smaller $2 \theta$ angles of the peaks at the $<002>$ and $<101>$ crystallographic orientations (as illustrated in Table 3).

To go deeper into the structural changes of the grown samples, additional calculations of the received XRD spectra are displayed in Table 4 . The following equations were used:

$$
\Phi: \text { mean crystallite size }=0.9 \lambda / \beta \cos (\theta) \text { with } \lambda=0.1542 \mathrm{~nm}
$$

where $\beta=$ FWHM of the peak at $2 \theta$ locations also identified and $\lambda$ is the wavelength of the $\mathrm{X}$-Ray radiation.

$$
\begin{gathered}
\varepsilon: \text { Microstrain }=\beta / 4 \tan (\theta) \\
\delta: \text { Dislocation density }=1 / \Phi^{2}
\end{gathered}
$$

According to Debey-Scherrer equations [35,36], the Unitary Cell Volume (UCV) is given by

$$
\mathrm{UCV}=(3 / 2)(5)^{1 / 2}\left(\mathrm{a}^{2} \mathrm{c}\right)
$$

Table 4. Crystallite sizes, strains, and dislocation densities calculated for $<002>$ crystalline orientation and UCV of the samples.

\begin{tabular}{ccccccc}
\hline SAMPLE & $\mathbf{2 \theta}$ & $\boldsymbol{\beta}$ (Degrees) & $\boldsymbol{\Phi}(\mathbf{n m})$ & $\varepsilon\left(\times \mathbf{1 0}^{-\mathbf{4}}\right)$ & $\left.\boldsymbol{\delta}\left(\mathbf{n m}^{-\mathbf{2}}\right) \mathbf{( 1 0}^{-\mathbf{4}}\right)$ & $\left.\mathbf{U C V}_{(\mathbf{n m}} \mathbf{3}\right)$ \\
\hline T0 & 34.5 & 0.4 & 20.4 & 5.6 & 23.9 & 0.1929 \\
T51 & 34.02 & 1.5 & 5.44 & 20.7 & 337.6 & 0.1909 \\
T52 & 33.98 & 1.24 & 6.58 & 17.1 & 230.7 & 0.1952 \\
T53 & 34.2 & 1.92 & 4.25 & 26.6 & 552.5 & 0.1906 \\
T101 & 33.8 & 1.66 & 4.92 & 22.7 & 413.9 & 0.1955 \\
T102 & 33.8 & 2 & 4.08 & 27.4 & 600.8 & 0.1935 \\
T103 & 33.9 & 2.64 & 3.09 & 36.2 & 1046.3 & 0.1956 \\
\hline
\end{tabular}

XRD analysis allows us to determine abrupt changes in the crystalline structures of the samples deposited at different powers as well as the different distances between the Te cathode and the substrate. Increasing the content of Te results in an irregular loss of crystalline quality of $\mathrm{w}-\mathrm{ZnO}$ in both sample series with respect to the reference. Higher Te content corresponds to greater effects on the crystalline structure of $\mathrm{ZnO}$. The great diminution of the particle size when Te content increases is presented in Table 4.

The most significant feature is the progressive increase in the dislocation density, which is associated with the presence of defects, impurities, atomic mismatches, and the stress with the nearest atoms produced by the possible Te incorporation into the $\mathrm{w}-\mathrm{ZnO}$ network, etc. It was previously reported that the increase in dislocation density acts as an indicator for the increase in sample defects [37].

Considering the relationships between the ion radii, valences, and electronegativity of the three elements, it is possible that both the substitution of $\mathrm{Zn}$ and $\mathrm{O}$ by Te atoms could occur in the $\mathrm{ZnO}$ network for low Te content. Nonetheless, substitution of $\mathrm{Zn}$ atoms by Te atoms should be easier according to solid solutions theory [38]. Evidently, the FWHM of the Bragg reflection $<002>$ increases from $0.4^{\circ}$ for the reference sample (T0) up to $2.64^{\circ}$ for the sample T103 (as illustrated in Table 4) with the highest content of Te. This fact is also indicative of the loss of crystalline quality of the matrix. This is further corroborated by the decrease of the mean crystallite sizes and the increase of the strain, although this is less significant than the behavior of the dislocation density. In addition, the mean value 
calculated for the UCV was around $0.19355 \mathrm{~nm}^{3}$; this parameter behaves differently in each series too. On the one hand, we were unable to identify a clear tendency in the A series. For example, while in sample T52 it is higher than that of $\mathrm{ZnO}$, samples T51 and T53 show UCV values lower than those of the $\mathrm{ZnO}$ reference. On the other hand, the UCV behavior observed in $\mathrm{B}$ series shows an increase for all samples with respect to the $\mathrm{ZnO}$ reference reaching a maximum deviation of $0.0027 \mathrm{~nm}^{3}$ for sample T103, which was grown at $\mathrm{P}_{\mathrm{Te}}=10 \mathrm{~W}$ with Te cathode located in the nearest position with respect to the substrate. In general, the values achieved by the UCV are close and, in some cases, coincide with those reported by other authors [10] in the range of the lowest concentrations of Te (series A), indicating the reduction of the lattice parameters particularly in samples T51 and T53. We think that in the series A there is a partial replacement of $\mathrm{Zn}$ by oxygen atoms in the $\mathrm{ZnO}$ network, while in series $\mathrm{B}$, a replacement of $\mathrm{Zn}$ by Te atoms in the network occurs.

From XRD results, we conclude that it is possible to obtain Te doping $\mathrm{ZnO}$ for the Te concentrations used in this work or lower by using the DC cosputtering magnetron technique while maintaining control of the sample compositions. As previously reported [26,27], these results could have relevant consequences for the band structure of the obtained compounds.

\subsection{Optical and Photoluminescence Properties}

The interpretation of photoluminescent (PL) properties of $\mathrm{ZnO}$ and $\mathrm{ZnO}$-based materials either in thin films form or in lower dimensionality is one of the most controversial topics in the field of semiconductors and materials in general. To date, there is no complete agreement about the origins of PL emissions from these materials in their different compositions, dimensions, and configurations. This is partially due to the large number of factors that influence these properties, among them: the starting sources and concentration of species participating in the growth processes, the growth techniques and procedures used, atmospheres, relative pressures, temperatures, etc. Detailed analysis of the PL response of $\mathrm{ZnO}$ reference is shown in Figure 4. Two very wide and intense bands are located in the UV and Visible ranges. The particularly asymmetric defect band (DB) is centered at about $2.25 \mathrm{eV}$.

In this figure, the existence of a large quantity of intrinsic defects in the reference sample is observed. The prominent emission at $3.26 \mathrm{eV}$ with $\mathrm{FWHM}=0.13 \mathrm{eV}$ and high intensity achieving almost $10^{4} \mathrm{a} . \mathrm{u}$. are located just in the frontier between violet and ultraviolet regions of the electromagnetic spectrum (EMS). This emission is associated with the excitonic transition, around $100 \mathrm{meV}$ smaller than the most accepted band gap energy (BG) value (3.36-3.37 eV) for this semiconductor. Nevertheless, the value $3.26 \mathrm{eV}$ is well in line with those previously reported for the $\mathrm{w}-\mathrm{ZnO}$ crystalline phase $[39,40]$.

Other two intense bands are centered in the orange-red $(2.03 \mathrm{eV})$ and in the green $(2.32 \mathrm{eV})$ regions of the EMS. The first one could be associated with the zinc vacancies $\left(\mathrm{V}_{\mathrm{Zn}}\right)$ or excess oxygen, as was previously reported [41,42]. The transition at $2.32 \mathrm{eV}$ falls almost in the center of the green band (GB). The origin of this band is probably the one that has caused the most controversy among numerous authors. While some attributed it to oxygen vacancies $\left(\mathrm{V}_{\mathrm{O}}\right)$ [43], others attributed it to zinc vacancies $\left(\mathrm{V}_{\mathrm{Zn}}\right)$ [44,45]. In this spectrum, it is also possible to identify a weak band centered at $3.1 \mathrm{eV}$ of very low intensity in the violet region associated with the transition energy of zinc interstitial $\left(Z_{\mathrm{ni}}\right)$ to valence band according to the full potential linear muffin-tin orbital method reported by Zeng et al. [46].

Optical transmission measurements (not shown) were made in the 190-800 $\mathrm{nm}$ range. Both sample series reflected high transparency $(>80 \%)$ in the $400-800 \mathrm{~nm}$ range. From Tauc Plot model [47], the direct BG of the samples were estimated (as shown in Table 5). It is well-accepted that all energy transitions observed in the interval from 2.9 to $3.19 \mathrm{eV}$ correspond to near band edge emissions (NBE) (see Table 5), taking into account Zeng et al. results [46]. The origin of these emissions are electronic transitions from the conduction band (CB) to $\mathrm{Zn}$ vacancies (VZn) near to the upper edge of the valence band (VB). All those 
transitions are in the violet range of the EMS, although for some samples, they appeared in the frontier of the ultraviolet range.

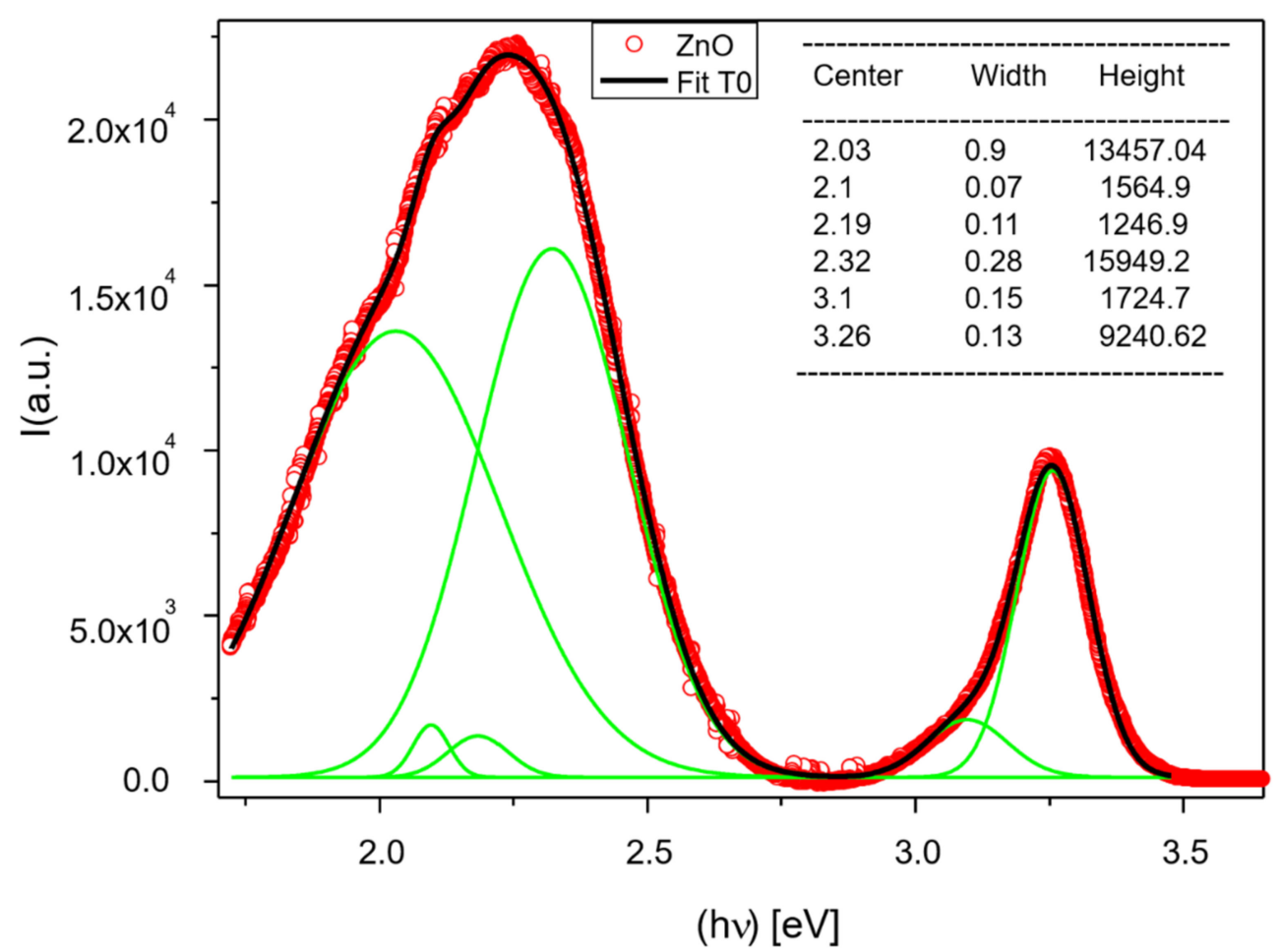

Figure 4. UV-visible photoluminescent (PL) spectrum of sample T0. It shows experimental points, integral Gaussian fitting curve, and single curves (green) that compose this acceptable fitting.

Table 5. Band gap energy (BG) values from transmittance measurements, and BG, Full Width at Half Maximum (FWHM), and NBE estimated from PL spectra.

\begin{tabular}{ccccc}
\hline SAMPLE & $\begin{array}{c}\text { BG } \\
\text { (Tauc Plot) } \\
{[\mathbf{e V}]}\end{array}$ & $\begin{array}{c}\text { BG from } \\
\text { PL } \\
{[\mathbf{e V}]}\end{array}$ & $\begin{array}{c}\text { FWHM } \\
\text { (BG-PL) } \\
{[\mathbf{e V}]}\end{array}$ & $\begin{array}{c}\text { NBE } \\
(\mathbf{e V})\end{array}$ \\
\hline T0 & 3.3 & 3.26 & 0.13 & 3.1 \\
T51 & 3.22 & 3.32 & 0.19 & 3.13 \\
T52 & 3.22 & 3.28 & 0.31 & 3.19 \\
T53 & 3.25 & 3.23 & 0.34 & 3.17 \\
T101 & 3.29 & 3.3 & 0.14 & 3.19 \\
T102 & 3.28 & 3.2 & 0.29 & - \\
T103 & 3.28 & 3.2 & 0.32 & - \\
\hline
\end{tabular}

Evidently, the BG values obtained from Tauc Plot calculations are slightly lower than that reported in the literature for $\mathrm{ZnO}$. On the other hand, the values obtained from PL spectra are slightly above or below of the value obtained for $\mathrm{ZnO}$ reference in this work. This relatively low BG value could be due to different interactions of chemical species participating in the synthesis, particularly, oxygen, zinc and tellurium atoms during the growth processes, which could passivate or quench between them in an uncontrollable way from the macroscopic point of view. In fact, tellurium incorporation in $\mathrm{ZnO}$ framework could substitute either $\mathrm{Zn}$ or $\mathrm{O}$ atoms during the synthesis, since it is possible that Te atoms serve as anionic dopant acting as passivating agent substituting, in particular, oxygen vacancies $\left(\mathrm{V}_{\mathrm{O}}\right)[20]$.

The resultant convolution PL curves obtained from the Gaussian fitting of the rest of the sample spectra are displayed in Figure 5a,b. 

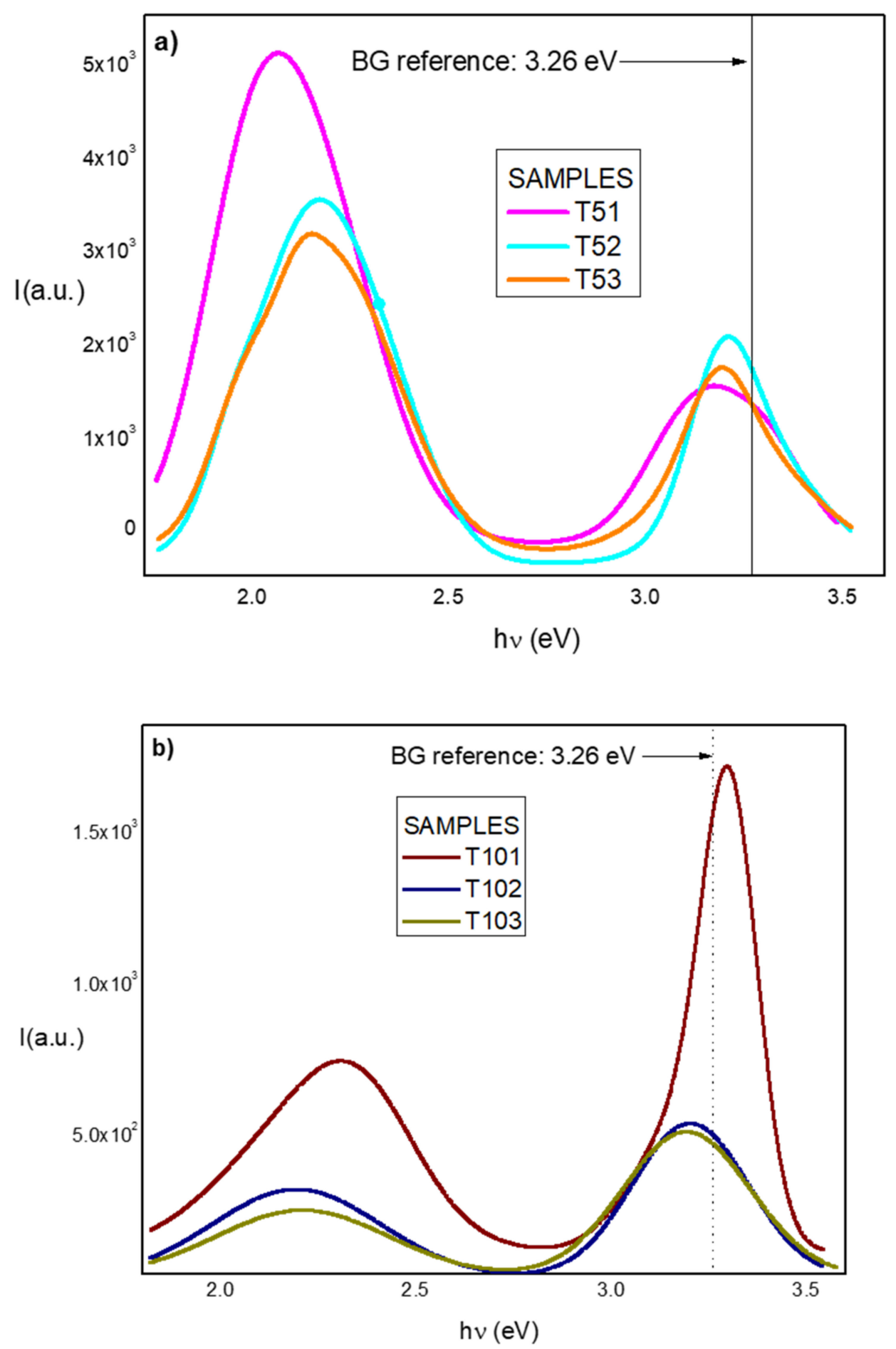

Figure 5. PL spectra of the (a) samples series A and (b) sample series B in the UV-Visible range at room temperature. Fitting of curves were obtained with determination coefficient $\left(R^{2}\right)$ values higher than $99 \%$.

In Figure 5a,b, the different shifts experienced in all spectra are illustrated. In sample series A, the BG shifts were between $60-20 \mathrm{meV}$ for samples T51 and T52 respectively, i.e., towards ultraviolet range with respect to the value obtained for the $\mathrm{ZnO}$ reference. In sample T53, the shift was $30 \mathrm{meV}$ towards the violet region. In sample series B, the BG shift of the samples T102 and T103 was towards the violet at approximately $60 \mathrm{meV}$. However, sample T101 had behaved very differently; its BG shift was towards ultraviolet reaching the value of $3.3 \mathrm{eV}$, equal to that obtained from the Tauc Plot for the reference sample, T0, and 
very near that of the $\mathrm{BG}$ standard value for $\mathrm{ZnO}$ at room temperature. The trend towards a decrease in the intensity of the transition from band to band (B-B) as well as the decrease in BG to around $3.2 \mathrm{eV}$ and the increase in FWHM when the tellurium content increases is justified by the increase in sample defects with the increase of the dislocation density, as shown in Table 4. In addition, an overlapping of delocalized defect states with the upper part of the VB could cause a rise in the VB edge, and therefore, a decreasing BG, as was reported previously [48].

On the contrary, samples T51 and T101 show the smallest increase in their FWHM values ( 0.19 and $0.14 \mathrm{eV}$, respectively), being very close to the obtained value for the reference sample, T0, equal to $0.13 \mathrm{eV}$. In sample T51, this latest observation is associated with a better conservation of the $\mathrm{ZnO}$ crystalline quality for the lowest Te content in agreement with XRD results. With sample T101, besides the above observations, this sample reflects the highest intensity for the B-B transition comparable to the intensity of $\mathrm{B}-\mathrm{B}$ transition observed in the $\mathrm{ZnO}$ reference, i.e., in the order of $10^{3}$ arbitrary units. This means the B-B transition was more three times larger than the BG values obtained in the rest of the sample series $B$. Accordingly, we can consider whether, for certain average concentrations of Tellurium, it will be possible to improve the crystalline quality of the $\mathrm{ZnOTe}$ compound. It could be interesting to further investigate the possible size quantum effects contributing to PL emissions due to a significant diminution of the crystallite sizes in the samples with the highest Tellurium content, of which some reports already exist [49]. As an antecedent in our case, the crystallite size diminished from $20.4 \mathrm{~nm}$ in T0 sample to $4.9 \mathrm{~nm}$ in sample T101 (as illustrated in Table 4).

Different GB transitions were observed in both sample series. This band is due to the existence of local energy levels in the band gap, and the intensity variations of these transitions [50] are determined by the concentration of intrinsic defects in the ZnOTe structures. As mentioned, the GB center in the undoped sample (T0) is located about $2.32 \mathrm{eV}$, being a very intense emission (inset in Figure 4). However, in samples T52, T101, and T102, the center's location occurs around $2.36 \mathrm{eV}$ and their intensities are almost thirteen times less than that observed in sample T0. Those values are very close to $2.38 \mathrm{eV}$ proposed for the center of GB [50]. B. Lin et. al. considered these emissions due to the transition from the bottom of the $C B$ to antisite oxygen $\left(\mathrm{O}_{\mathrm{Zn}}\right)$ in the $B G$. According to Y. M. Sun's calculi [50], the transitions in the range from 2.19-2.23 eV can be attributed to interstitial oxygen $\left(\mathrm{O}_{\mathrm{i}}\right)$ defects within the GB, which were observed in all samples except in T51 and T102. Nevertheless, different experiments to investigate the origin of $\mathrm{PL}$ bands in $\mathrm{ZnO}$ single crystals determined that zinc vacancies $\left(\mathrm{V}_{\mathrm{zn}}\right)$ are responsible for maximum green emissions of samples grown in oxygen-rich atmospheres [51]. Despite the polycrystallinity of our samples, this fact is probably just as present in our results because they were grown in oxygen-rich atmosphere, and RBS results (as illustrated in Table 2) confirmed the excess of oxygen in both sample series. Other experiments are currently underway to confirm this hypothesis.

In all doped samples, it was possible to identify some transitions in the range of the lower energies, from 2.1-2.18 eV. This range encompasses the orange-yellow region of the $\mathrm{E}$ MS and were associated with interstitial oxygen $(\mathrm{Oi})$ in the reported results on the growth of $\mathrm{ZnO}$ at different temperatures and enhanced in oxygen-rich atmosphere [52]. PL spectra in both sample series also show transitions corresponding to a red band (RB) in the range below $2 \mathrm{eV}$; however, these transitions are not frequently present in $\mathrm{ZnO}$ emissions [43] so they probably appear here as a small fraction of contaminants.

The shifts towards lower energies observed in the sample's BG as well as the possible improvement of $\mathrm{ZnOTe}$ crystalline quality with Tellurium content can be very interesting sources for applications by using DC magnetron cosputtering from individual $\mathrm{Zn}$ and Te cathodes and improving the oxygen atmosphere control. 


\section{Conclusions}

Two sample series of the ternary compound $\mathrm{ZnOTe}$ in thin films form were grown using DC magnetron cosputtering technique starting from highly pure independent zinc and tellurium targets in a controlled oxygen/argon atmosphere at room temperature. The technique used in conjunction with the experimental configuration for obtaining this type of compound and the detailed analysis of its structure and optical properties are part of this work's novelty. The use of a constant power on the Zn cathode and two different powers on the Te cathode as well as the variation of the distance between the latter and the substrate allowed us to study the influence of these parameters on the structure, composition, and macroscopic properties of the samples. Under these conditions, the most important effect was the variable amount of Te incorporated into each sample. In that sense, different chemical compositions for each, including a homogeneous distribution of Te along their thicknesses and a variable amount of excess oxygen, were determined by RBS experiments. On the other hand, the formation of the $\mathrm{ZnO}$ hexagonal phase in all samples was identified by mean XRD spectra. ZnO band gap energy obtained from PL spectra was estimated at $3.26 \mathrm{eV}$, well in agreement with previously obtained values. Other highlighted results include the relative loss of $\mathrm{ZnO}$ crystalline quality due to the increasing Te content, and in general, a band gap energy shift towards the lowest energies, which may account for the incorporation of Te into the ZnOcrystalline network. Nevertheless, in the samples with the lowest Te content within each series (samples T51 and T101), the band gap energy values were 3.32 and $3.3 \mathrm{eV}$, respectively, almost coincident with the standard value reported $(3.36 \mathrm{eV})$ for the $\mathrm{w}-\mathrm{ZnO}$ phase at room temperature. This suggests the possibility of certain improvements in $\mathrm{ZnOTe}$ crystallinity when moderate quantities of Te are incorporated in the $\mathrm{ZnO}$ network. We expect there exists a critical value of the Te concentration that helps to obtain optimal effects in the formation of interbands in the BG that are of great interest for solar cell efficiency. It is a new challenge of basic research to obtain a better understanding of the physics-chemistry of ZnOTe compounds obtained through the DC magnetron cosputtering technique used here.

Author Contributions: Writing—original draft, O.S.; Writing—review \& editing, M.H.-V. All authors have read and agreed to the published version of the manuscript.

Funding: This research received no external funding.

Institutional Review Board Statement: Not applicable.

Informed Consent Statement: Not applicable.

Data Availability Statement: The relevant data is contained within the article.

Acknowledgments: This work was supported by the Ministerio de Ciencia, Innovación y Universidades of Spain through the Project RTI2018-095137-B-I00. Authors acknowledge Ana Urbieta (UCM) for PL measurements, A. Climent Font for RBS measurements, and Nair López for her interesting suggestions.

Conflicts of Interest: The authors declare no conflict of interest.

\section{References}

1. Lu, F.; Cai, W.; Zhang, Y. ZnO hierarchical micro/nanoarchitectures: Solvothermal synthesis and structurally enhanced photocatalytic performance. Adv. Funct. Mat. 2008, 18, 1047-1056. [CrossRef]

2. Pietrzyk, M.A.; Wierzbick, A.; Zielony, E.; Pieniazek, A.; Szymon, R.; Placzek-Popko, E. Fundamental studies of ZnO nanowires with $\mathrm{ZnCdO} / \mathrm{ZnO}$ multiple quantum wells grown for tunable light emitters. Sens. Actuators $A$ 2020, 315, 112305. [CrossRef]

3. Chou, H.-C.; Yang, K.-D.; Xiao, S.-H.; Patil, R.A.; Lai, C.-C.; Vincent, W.-C.; Ho, C.-H.; Liouc, Y.; Ma, Y.-R. Temperature-dependent ultraviolet photoluminescence in hierarchical $\mathrm{Zn}, \mathrm{ZnO}$ and $\mathrm{ZnO} / \mathrm{Zn}$ nanostructures. Nanoscale 2019, 11, 13385-13396. [CrossRef] [PubMed]

4. Furuta, M.; Kamada, Y.; Kimura, M.; Shimakawa, S.-I.; Kawaharamura, T.; Wang, D.; Li, C.; Fujita, S.; Hirao, T. Photocurrent and persistent photoconductivity in zinc oxide thin-film transistors under ultraviolet-light irradiation. J. Appl. Phys. 2011, 50, 110204. [CrossRef] 
5. Tiginyanu, I.; Ghimpu, L.; Gröttrup, J.; Postolache, V.; Mecklenburg, M.; Stevens-Kalceff, M.A.; Ursaki, V.; Payami, N.; Feidenhansl, R.; Schulte, K.; et al. Strong light scattering and broadband (UV to IR) photoabsorption in stretchable 3D hybrid architectures based on aerographite decorated by $\mathrm{ZnO}$ nanocrystallites. Sci. Rep. 2016, 6, 1-11. [CrossRef]

6. Postica, V.; Gröttrup, J.; Adelung, R.; Lupan, O.; Mishra, A.K.; de Leeuw, N.H.; Ababii, N.; Carreira, J.F.C.; Rodrigues, J.; Sedrine, N.B. Nanosensors: Multifunctional materials: A case study of the effects of metal doping on $\mathrm{ZnO}$ tetrapods with bismuth and tin oxides. Adv. Funct. Mater. 2017, 27, 1604676.

7. Kim, H.; Gilmore, C.M.; Horwitz, J.S.; Piqué, A.; Murata, H.; Kushto, G.P.; Schlaf, R.; Kafafi, Z.H.; Chrisey, D.B. Transparent conducting aluminum-doped zinc oxide thin films for organic light-emitting devices. Appl. Phys. Lett. 2000, 76, 259. [CrossRef]

8. Lee, S.-H.; Han, S.-H.; Jung, H.S.; Shin, H.; Lee, J.; Noh, J.-H.; Lee, S.; Cho, I.-S.; Lee, J.-K.; Kim, J.; et al. Al-doped ZnO thin film: A new transparent conducting layer for ZnO nanowire-based dye-sensitized solar cells. J. Phys. Chem. 2010, 114, 7185-7189. [CrossRef]

9. Kaps, S.; Bhowmick, S.; Gröttrup, J.; Hrkac, V.; Stauffer, D.; Guo, H.; Warren, O.I.; Adam, J.; Kienle, I.; Minor, A.M.; et al. Piezoresistive response of quasi-one-dimensional $\mathrm{ZnO}$ nanowires using an in situ electromechanical device. ACS Omega 2017, 2, 2985-2993. [CrossRef]

10. Shanmugan, N.; Suthakaran, S.; Kannadasan, N.; Kumar, K.S. Synthesis and characterization of Te doped ZnO nanosheets for photocatalytic application. J. Heterocycl. 2015, 1, 1-6.

11. López, N.; Reichertz, L.A.; Yu, K.M.; Campman, K.; Walukiewicz, W. Engineering the electronic band structure for multiband solar cells. Phys. Rev. Lett. 2011, 106, 28701. [CrossRef]

12. Park, S.H.; Minegishi, T.; Oh, D.C.; Chang, J.H.; Taishi, T.; Yonenaga, I.; Yao, T. P-type conductivity control of heteroepitaxially grown ZnO films by $\mathrm{N}$ and Te cooping and thermal annealing. J. Cryst. Growth 2013, 363, 190-194. [CrossRef]

13. Tang, K.; Gu, S.L.; Wu, K.P.; Zhu, S.M.; Ye, J.D.; Zhang, R.; Zheng, Y.D. Temperature-dependent photoluminescence of ZnO films codoped with tellurium and nitrogen. J. Appl. Phys. 2012, 112, 103534. [CrossRef]

14. Ozgür, Ü.; Hofstetter, D.; Morkoç, H. ZnO devices and applications: A review of current status and future prospects. Proc. IEEE 2010, 98, 1255-1268. [CrossRef]

15. Walukiewicz, W.; Shan, W.; Yu, K.M.; Ager, J.W.; Haller, E.E.; Miotkowski, I.; Seong, M.J.; Alawadhi, H.; Ramdas, A.K. Interaction of localized electronic states with the conduction band: Band anticrossing in II-VI semiconductor ternaries. Phys. Rev. Lett. 2000, 85, 552. [CrossRef]

16. Yu, K.M.; Walukiewicz, W.; Ager, J.W.; Bour, D.; Farshchi, R.; Dubon, D.O.; Li, S.X.; Sharp, I.D.; Haller, E.E. Multiband GaNAsP quaternary alloys. Appl. Phys. Lett. 2006, 88, 92110. [CrossRef]

17. López, N.; Yu, K.M.; Tanaka, T.; Walukiewicz, W. Multicolor electroluminescence from intermediate band solar cell structures. Adv. Energy Mater. 2016, 6, 1501820. [CrossRef]

18. Sonmezoglu, S.; Akman, E. Improvement of physical properties of ZnO thin films by tellurium doping. Appl. Surf. Sci. 2014, 318, 319-323. [CrossRef]

19. Jamali-Sheini, F.; Yousefi, R.; Mahmoudian, M.R.; Ali, B.N.; Saaedi, A.; Huang, N.M. Facile synthesis of different morphologies of Te-doped ZnO nanostructures. Ceram. Int. 2014, 40, 7737-7743. [CrossRef]

20. Sahu, R.; Dileep, K.; Negi, D.S.; Nagaraja, K.K.; Shetty, S.; Datta, R. Structural and optical property characterization of epitaxial ZnO: Te thin films grown by pulsed laser deposition. J. Cryst. Growth 2015, 410, 69-76. [CrossRef]

21. Tapily, K.; Gu, D.; Boumgart, H.; Namkoong, G.; Stegall, D.; Elmustafa, A.A. Mechanical and structural characterization of atomic layer deposition-based ZnO films. Semicond. Sci. Tech. 2011, 26, 115005-115007. [CrossRef]

22. Nagajurna, Y.; Hsiao, Y.-J. Au doping ZnO nanosheets sensing properties of ethanol gas prepared on MEMS device. Coatings 2020, 10, 945.

23. Rana, A.H.S.; Kim, H.-S. $\mathrm{NH}_{4} \mathrm{OH}$ Treatment for an optimum morphological trade-off to hydrothermal Ga-doped n-ZnO/p-Si heterostructure characteristics. Materials 2018, 11, 37.

24. Ting, M.; Yu, K.M.; Jaquez, M.; Sharp, I.D.; Ye, Y.; Sgercrantz, N.; Greif, R.; Mao, S.S.; Ping, L.C.; Walukiewicz, W. ZnO $1-x$ Te $_{x}$ highly mismatched alloys beyond the dilute alloy limit: Synthesis and electronic band structure. J. Appl. Phys. 2019, 125, 155702. [CrossRef]

25. Singh, S.P.; Arya, S.K.; Pandey, P.; Malhotra, B.D.; Saha, S.; Sreenivas, K.; Gupta, V. Cholesterol biosensor based on rf sputtered zinc oxide nanoporous thin film. Appl. Phys. Lett. 2007, 91, 63901-63903. [CrossRef]

26. Khosravi-Nejad, F.; Teimouri, M.; Jafari Marandi, S.; Shariati, M. The highly sensitive impedimetric biosensor in label free approach for hepatitis B virus DNA detection based on tellurium doped ZnO nanowires. Appl. Phys. A 2019, 125, 616. [CrossRef]

27. Lee, D.U.; Kim, S.P.; Lee, K.S.; Pak, S.W.; Kim, E.K. Band gap modulation of $\mathrm{ZnTe}_{1-\mathrm{x}} \mathrm{O}_{\mathrm{x}}$ alloy film by control of oxygen gas flow rate during reactive magnetron sputtering. App. Phys. Lett. 2013, 103, 263901.

28. Liua, P.; Ho, C.Y.; Egbo, K.O.; Li, Z.H.; Xu, C.K.; Yu, K.M. Optoelectronic properties and doping of magnetron sputtered highly mismatched $\mathrm{ZnO}_{1-\mathrm{x}} \mathrm{Te}_{\mathrm{x}}$ alloy thin films. J. Alloy. Compd. 2021, 852, 156950. [CrossRef]

29. Sánchez, O.; Climent, A.; Fernández Barcia, M.; Martínez Sacristán, O.; Hernández-Vélez, M. ZnO ${ }_{1-\mathrm{x}} \mathrm{Te}_{\mathrm{x}}$ thin films deposited by reactive magnetron co-sputtering: Composition, structure and optical properties. MRS Adv. 2017, 2, 3111-3116. [CrossRef]

30. Huan-Sheng, C.; Jiayong, H.T.; Fujia, Y. Nuclear instruments and methods in physics research section B: Beam interactions with materials and atoms. Nucl. Instrum. Methods B 1993, 83, 449-453. [CrossRef]

31. Mayer, M. SIMNRA User's Guide; IPP 9/113; Max-Planck-Institut fur Plasmaphysik: Garching, Germany, 1997. 
32. ICDD. PCPDFWIN; 2.2 Version; International Centre for Diffraction Data: Newtown Square, PA, USA, 2001.

33. Kamran, M.A. Novel low-temperature synthesis and optical properties of 1D-ZnTe nanowires. J. Sci. Adv. Mater. Dev. 2018, 3, 226-229. [CrossRef]

34. Shaabana, E.R.; Kansal, I.; Mohamed, S.H.; Ferreira, J.M.F. Microstructural parameters and optical constants of ZnTe thin films with various thicknesses. Phys. B 2009, 404, 3571-3576. [CrossRef]

35. Jalili, S.; Hajakbari, F.; Hojabri, A. Effect of silver thickness on structural, optical and morphological properties of nanocrystalline Ag/NiO thin films. J. Theor. Appl. Phys. 2018, 12, 15-22. [CrossRef]

36. Hajakbari, F.; Shafieinejad, F. Structural, morphological, electrical, and optical properties of silver thin films of varying thickness deposited on cupric oxide. Jpn. J. Appl. Phys. 2016, 55, 35503. [CrossRef]

37. Ilican, S.; Caglar, Y.; Caglar, M. Preparation and characterization of $\mathrm{ZnO}$ thin films deposited by sol-gel spin coating method. $J$. Optoelectron. Adv. Mater. 2008, 10, 2578-2583.

38. Callister, W.D., Jr. Materials Science and Engineering, 4th ed.; John Wiley and Sons, Inc.: Hoboken, NJ, USA, 1997.

39. Özgür, Ü.; Ya, I.A.; Liu, C.; Teke, A.; Reshchikov, M.A.; Doğan, S.; Avrutin, V.; Cho, S.-J.; Morkoç, H. A comprehensive review of ZnO materials and devices. J. Appl. Phys. 2005, 98, 41301. [CrossRef]

40. Shan, F.K.; Liu, G.X.; Lee, W.J.; Lee, G.H.; Kim, I.S.; Shin, B.C. Aging effect and origin of deep-level emission in ZnO thin film deposited by pulsed laser deposition. Appl. Phys. Lett. 2005, 86, 221910. [CrossRef]

41. Djurisic, A.B.; Leung, Y.H.; Tam, K.H.; Ding, L.; Ge, W.K.; Chen, H.Y.; Gwo, S. Green, yellow, and orange defect emission from ZnO nanostructures: Influence of excitation wavelength. Appl. Phys. Lett. 2006, 88, 103107. [CrossRef]

42. García, P.F.; McLean, R.S.; Reilly, M.H.; Nunes, G. Transparent ZnO thin-film transistor fabricated by rf magnetron sputtering. Appl. Phys. Lett. 2003, 82, 1117.

43. Mass, J.; Avella, M.; Jimenez, J.; Callahan, M.; Grant, E.; Rakes, K.; Bliss, D.; Wang, B. New Materials and Processes for Incoming Semiconductor Technologies; Dueñas, S., Castán, H., Eds.; Transworld Research Network: Kerala, India, 2006; p. 113. ISBN 81-7895-241-6.

44. Kohan, A.F.; Ceder, G.; Morgan, D.; van de Walle, C.G. First-principles study of native point defects in ZnO. Phys. Rev. B 2000, 61, 15019-15022. [CrossRef]

45. Chen, H.; Gu, S.; Tang, K.; Zhu, S.; Zhu, Z.; Ye, J.; Zhang, R.; Zheng, Y. Origins of green band emission in high-temperature annealed N-doped ZnO. J. Lumin. 2011, 131, 1189. [CrossRef]

46. Zeng, H.; Li, Z.; Cai, W.; Liu, P. Strong localization effect in temperature dependence of violet-blue emission from ZnO nanoshells. J. Appl. Phys. 2007, 102, 104307. [CrossRef]

47. Viezbicke, B.D.; Patel, S.; Davis, B.E.; Birnie, D.P. Evaluation of the Tauc method for optical absorption edge determination: ZnO thin films as a model system. Phys. Status Solidi B 2015, 252, 1700. [CrossRef]

48. Wang, J.; Wang, Z.; Huang, B.; Ma, Y.; Liu, Y.; Qin, X.; Zhang, X.; Dai, Y. Oxygen vacancy induced band-gap narrowing and enhanced visible light photocatalytic activity of ZnO. ACS Appl. Mater. Interfaces 2012, 4, 4024-4030. [CrossRef]

49. Studenikin, S.A.; Golego, N.; Cocivera, M. Fabrication of green and orange photoluminescent, undoped ZnO films using spray pyrolysis. J. Appl. Phys. 1998, 84, 2287. [CrossRef]

50. Lin, B.; Fu, Z.; Jia, Y. Green luminescent center in undoped zinc oxide films deposited on silicon substrates. Appl. Phys. Lett. 2001, 79, 943-945. [CrossRef]

51. Berseth, T.M.; Svenson, B.G.; Kusnetsov, A.Y.; Klason, P.; Zhao, Q.X.; Willander, M. Temperature-dependent photoluminescence of Li-doped ZnO. Appl. Phys. Lett. 2006, 89, 262112.

52. Rodnyi, P.A.; Khodyuk, I.V. Optical and luminescence properties of zinc oxide (review). Opt. Spectrosc. 2011, 111, 776-785. [CrossRef] 